\title{
Comentário a \\ “HistóRIA dA CIÊNCIA, EPISTEMOLOGIA E DIALÉTICA": CIÊNCIA, ONTOlOGIA E REALIDADE: MARX PARA ALÉM DA DIALÉTICA
}

Antônio José Lopes Alves ${ }^{1}$

Referência do texto comentado: SILVA, Edson Pereira; ARCANJO, Fernanda Gonçalves. História da ciência, epistemologia e dialética. Trans/Form/Açáo: revista de filosofia da Unesp, v. 44, n. 2, 2021, p. $149-174$.

Instado por Trans/form/açāo a produzir um breve comentário a "História da Ciência, Epistemologia e Dialética", apresenta-se aqui um conjunto de glosas, cujo mote é tanto registrar algumas observaçóes críticas ao artigo quanto explicitar sucintamente os lineamentos que nortearam a leitura, o estudo e a crítica daquele trabalho.

Inicialmente, questiona-se a tentativa de conversação aproximativa entre Marx e Bachelard. Em que sentido poderia uma aproximação dessa natureza ser pertinente e autorizada pelos pressupostos de ambos os autores?

Em Marx, temos uma propositura científica de caráter analítico e materialista, a qual parte da pressuposição de que as categorias são formas

${ }^{1}$ Professor Titular da Universidade Federal de Minas Gerais (UFMG) e docente do Colégio Técnico, credenciado no Programa de Pós-Graduação em Educação: conhecimento e inclusão social e no Mestrado Profissional em Educação e Docência, ambos da Universidade Federal de Minas Gerais (UFMG), Belo Horizonte, MG - Brasil. (D) https://orcid.org/0000-0002-6365-3514. E-mail: ajlopesalves@gmail.com.

https://doi.org/10.1590/0101-3173.2021.v44n2.12.p175

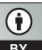


de ser, determinaçóes da existência (Daseinsformen, Existenzbestimmungen) (MARX, 2011, p. 59), de que cientificamente reproduzem o referente como concreto pensado. No crítico francês da epistemologia, tem-se a independência relativa do objeto do conhecimento, conceitualmente elaborado, em relação à realidade mesma. $\mathrm{O}$ objeto de conhecimento é desconectado do existente, é um produto da operatividade técnico-conceitual da atividade científica, não ponderável pela realidade. Num, o pressuposto ontológico da objetividade finito tornado objeto. Noutro, o conceito como produto de uma atividade que não é a rigor parametrizada pela objetividade, nem da totalidade real, nem do recorte experimental.

Ademais, partindo do entendimento do materialismo marxiano e de seu "estatuto ontológico" (CHASIN, 2009, p. 39-86), julga-se igualmente pertinente tecer uns comentários acerca de outro aspecto problemático do texto: existiria um paradigma científico do "materialismo histórico-dialético"? Um esquema de inteligibilidade cunhado por Marx e Engels, a partir da apropriação crítica que supostamente fizeram da dialética hegeliana? Este é um tema de questionamento recorrente tanto nos círculos marxológicos quanto fora deles, interna ou externamente à tradição marxista. Aliás, é importante ressaltar que a formulação de tal padrão de referência é algo jamais enunciado por Marx e somente bem depois de sua morte, na passagem do século XIX para o XX, encontra elaboração (CERQUEIRA, 2015, p. 826).

Marx jamais manejou os elementos da dialética como um conjunto de regras metodológicas ou lógicas, e sim como nome geral de aspectos que objetivamente podem ser flagrados, discernidos e compreendidos na analítica do objeto. Afora isso, como encadeamento das categorias enquanto processo transitivo de desenvolvimento, modo de apresentação por meio do qual se expóe o evolver do processo. Portanto, a dialeticidade existente no Forschungsweise não é necessariamente a mesma do Darstellungsweise (MARX, 2013, p. 90) e, por sua vez, a do Daseinsweise é diferente simultaneamente de ambos os modos pelos quais o existente finito realmente existente é apreendido e exposto (MARX, 2011, p. 54-55).

O caráter materialista de Marx se formula pela crítica do fundamento especulativo (a identidade entre Ser e Ideia) que propriamente apenas ao logicismo, algo que preocupava mais a Engels, na tentativa de encontrar à cientificidade moderna uma ancoragem em supostas leis universais da dialética. Acerca disso, veja-se em Dialética da Natureza, por exemplo, a indicação, para cada relação natural objeto das ciências, um princípio dialético 
que estaria cosmicamente nelas pressuposto (ENGELS, 1979, p. 34-40). Algo deveras diferente da forma como Marx toma a questão; não "provar" as leis da dialética, por meio da cientificidade corrente. Quando muito, assinalava que diversos insights hegelianos, originalmente expressos especulativamente, quando despidos de seu caráter lógico-idealista, acabavam sendo confirmados por diferentes investigaçóes das variadas ciências.

À especulação hegeliana Marx produz uma crítica de caráter ontológico, a recusa da identidade entre racionalidade e realidade. Para Marx, o real não é "racional", no sentido de uma lógica de raison d'être. Certamente, não é um caos, possui uma dada configuração ou concatenação de determinações, mas estas não necessariamente se coadunam ou se identificam com apriorismos lógicos ou teoréticos. Marxianamente, não se trata de traduzir a lógica hegeliana em termos materialistas, nem de "convertê-la ao materialismo", porém, de encontrar a "lógica" específica da coisa específica, de reproduzir conceitualmente, por meio da "transposição" e da "tradução" em categorias, a malha categorial que in rebus que constitui o por-si do que se estuda, em sua independência aos atos pelos quais pode ser modificado ou conhecido.

Não significa uma adequatio e sim uma aproximação reprodutiva de caráter categorial. Conhecer é uma atividade humana peculiar, um conjunto de atos social e historicamente determinados e possibilitados por condiçóes societárias materiais e espirituais, as quais dependem dos modos pelos quais os seres humanos vivos e ativos operam na realidade e produzem seus meios de existência. Transpor e traduzir são dois pôres que constituem a apreensão como pensamento daquilo que está-aí, do Dasein, do existente. São aproximaçóes efetivadas, cumulativamente ou não, pelas quais o mundo, em sua diversidade, é apropriado mental e conceitualmente. Ou seja, trata-se do capturar a espessura ontológica dos processos finitos em sua especificidade, sua differentia specifica. Nunca do acomodar a diversidade da realidade dentro de um molde ou esquema genérico explicativo a priori, seja este de talhe formal ou "dialético". O que, ressalte-se, nada tem de empirismo, pois os conceitos não são resultado de meros decalques ou impressôes produzidas por um mundo obscuro e/ou caótico, em nossas condições transcendentais ou neuronais de percepção.

Resulta daí que, no contexto da elaboração marxiana, o conhecimento não tem uma resolução epistêmica ou metodológica, mas sim ontológica. Consequentemente, a dialética não é nem sustentação metodológica tampouco um suposto princípio racional a atravessar o mundo e a consciência que o 
faceia. Marx não "lê dialeticamente" a realidade econômica ou histórica, nem pressupóe ser "a" contradição o elemento essencial, "a verdade" do mundo. A contradição é, antes, aspecto apreendido na análise, no escrutínio de relaçóes e processos. Não por azar, uma das imagens mais recorrentes utilizadas por Marx para caracterizar seu padrão teórico é a do anatomista, como se observa a partir de meados de 1843 até os seus últimos manuscritos (ALVES, 2015a, p. 201-232).

Finalizando, considera-se agora o modo como o teor ontológico das proposituras marxianas é tratado no artigo comentado. A determinação do pensar as coisas pelo seu ser não é sequer referida explicitamente. O "aspecto" ontológico da prática científica é desnaturado como uma mera metacrítica externa ao processo de produção do conhecimento, como um sociologismo do conhecimento. Consequentemente, reduz-se a espessura do real que continua a existir fora da cabeça de quem a pesquisa, e a se impor como metro da aproximação, a uma expressão direta dos limites da sociabilidade, o que empobrece igualmente o entendimento das relaçóes entre cientificidade e sociedade e da vida social como objeto de pesquisa em Marx.

Esse equívoco se explicita inclusive como as citaçôes marxianas são apostas ao texto, sem remetimento ao contexto original. Tome-se, por exemplo, a da página 55 da edição usada. Diferentemente do que é discutido no parágrafo, não se trata lá da questão da determinação social do pensamento, tema igualmente importante para a discussão das formações ideais (ALVES, 2015b, p. 231-246.). É acerca da determinação do conceito pela efetividade: situa-se a sociedade aqui na posição de objeto da economia política e não de condição à cientificidade. Por isso, Marx emprega o termo Subjekt, sujeito, que equivale a referente concreto e finito das categorias da economia política e de sua crítica da economia política (MARX, 2011, p. 55).

Ademais, parece não se atinar existam, pois, "dois concretos" em jogo: 1) o finito tal este é, em sua forma de existência - social - objetiva, sejam os produtos do trabalho humano como mercadoria, seja a população como totalidade contraditoriamente articulada de suas classes e estratos; 2) a concretude "re-produzida" como concreto pensado, produção de formas ideais exprimindo a seu modo, conceitualmente, a articulação das Daseinsformen na realidade social. Caso contrário, ou bem teríamos Hegel e a concretude como produto do ato de pensá-la, ou bem Weber e as abstraçóes razoáveis reduzidas a tipos ideais que formatam no, e para o, pensamento uma realidade por si absolutamente caótica e sem concatenação imanente. Que a imanência 
seja contraditória, não resulta daí que esta seja um caos de indeterminação, mas sim que a articulaçáo que os elementos apresentam entre seus predicados mais importantes um caráter de contradição imanente e dinâmico, no desenvolvimento de seu peculiar modo de existência de articulação das formas de ser que a perfazem.

\section{REFERÊNCIAS}

ALVES, Antônio J. L. A metáfora do anatomista e a possibilidade do conhecimento objetivo da realidade social em Marx. Princípios - Revista de Filosofia. UFRN, Natal, v. 22, n. 38, maio/ago. 2015a, p. 201-232.

ALVES, Antônio J. L. Ontologia, Standpunkt e ideologia: para além das teorias do falso. In: TORRIGLIA, Patrícia L. (org.). Ontologia e crítica do tempo presente. Florianópolis: Editoria Em Debate - UFSC, 2015b, p. 231-246.

CERQUEIRA, Hugo E. A. da G. Breve história da edição crítica das obras de Karl Marx. Revista Brasileira de Economia Política, v. 35, n. 4, 2015, p. 821-844.

CHASIN, José. Marx: estatuto ontológico e resoluçấo metodológica. São Paulo: Boitempo, 2009.

ENGELS, Friedrich. Dialética da natureza. Rio de Janeiro: Paz e Terra, 1979.

MARX, Karl. Grundrisse - Manuscritos econômicos de 1857-58: esboços da crítica da economia política. São Paulo: Boitempo, 2011.

MARX, Karl. O capital - crítica da economia política. Livro I: o processo de produção do capital. São Paulo: Boitempo, 2013.

SILVA, Edson Pereira; ARCANJO, Fernanda Gonçalves. História da ciência, epistemologia e dialética. Trans/Form/Ação: revista de filosofia da Unesp, v. 44, n. 2, 2021, p. $149-174$.

Recebido: 12/9/2020

Aceito: 19/9/2020 
ALVES, A. J. L. 